\title{
ANALISIS PENERAPAN SISTEM INFORMASI AKUNTANSI DALAM MENDUKUNG PENGENDALIAN INTERNAL PEMBERIAN KREDIT PADA PT. BANK TABUNGAN NEGARA (BTN) DI KOTA BANDA ACEH
}

\author{
Restu Febi Purwono*1, Rudy Fachruddin" ${ }^{* 2}$ \\ ${ }^{1,2}$ Program Studi Akuntansi Fakultas Ekonomi dan Bisnis Universitas Syiah Kuala \\ e-mail: restufeno19@gmail.com ${ }^{* 1}$,rudy_ipah@unsyiah.ac.id ${ }^{* 2}$
}

\begin{abstract}
This study aims to analyze the future of accounting information systems in supporting the internal control of lending carried out by PT Bank Tabungan Negara Banda Aceh Branch. The type of investigation in this study is qualitative research, while the research method that used in this study is descriptive. The data collection technique in this study is through interviews and documentation.The credit accounting information system which implemented by PT Bank Tabungan Negara (BTN) Banda Aceh is adequate and the credit accounting information system has played a role in supporting internal control, and internal control at Bank BTN Banda Aceh has been running effectively.
\end{abstract}

Keywords: Accounting Information Systems, Internal Control, Credit.

\section{Pendahuluan}

Modal merupakan syarat utama bagi pengusaha untuk memulai sebuah bisnis. Di era globalisasi ini untuk membuka usaha bisnis membutuhkan modal yang cukup besar. Modal yang tidak cukup akan membuat usaha bisnis terkendala di kemudian hari. Hal ini yang menjadi pertimbangan para pengusaha utnuk mengajukan pinjaman modal. Bank merupakan salah satu alternatif untuk mendapatkan pinjaman modal.

Selaras dengan Undang-undang Perbankan No. 10 tahun 1998, bank adalah entiti perniagaan yang mengumpulkan dana dari penduduk dalam bentuk deposit dan mennyalurkanya di kalangan penduduk berupa hutang atau bentuk lain untuk memperbaiki taraf hidup penduduk. Peranan bank sangat diharapkan oleh masyarakt untuk menunjang penyediaan modal usaha melalui jasa kredit.

PT Bank Tabungan Negara merupakan syarikat perbankan punya negara. BTN dengan perencanaan bisnis yang lebih terarah akan membantu semua kebutuhan masyarakat saat ini. BTN berkomitmen untuk menjadi Bank yang melayani dan mendukung sektor perumahan melalui tiga produk utama yaitu perbankan perseorangan, bisnis, dan syariah (https://www.btn.co.id).

BTN mempunyai beberapa produk kredit untuk membantu kebutuhan masyarakat yaitu seperti pinjaman bangunan, pinjaman khusus, pinjaman ringan, pinjaman usaha dan pinjaman UMKM. Pemberian kredit tidak akan lepas dari risiko kerugian, seperti timbulnya kredit macet yang disebabkan oleh pelanggan yang tidak mampu membayar pinjaman tepat waktu. Sejumlah besar kredit macet adalah problem yang banyak mempengaruhi kondisi keuangan bank.

Resiko kredit macet dapat diminimalisir dengan menjalankan pengendalian internal yang efektif dan efisien. Pengendalian internal merupakan proses yang dipengaruhi oleh lembaga pengarah, manajemen dan personel lain yang dibuat untuk memberikan jaminan yang wajar mengenai pencapaian tujuan yang berkaitan dengan operasi, pelaporan dan keterpatuhan. Pengendalian Internal tidak terlepas dari sistem informasi akuntansi. Sistem informasi akuntansi adalah sistem yang mengumpulkan, mencatat, menyimpan, dan memproses data yang diberikan kepada pembuat keputusan (Romney, 2014:10).

Pengendalian internal dan sistem informasi akuntansi dibutuhkan oleh berbagai pihak di perusahaan dalam pengambilan keputusan pemberian kredit kepada nasabah. Tujuan sistem informasi akuntasi yaitu informasi yang dihasilkan oleh sistem dapat membantu manajemen dan para pemakainya dalam pengambilan keputusan. Sistem informasi akuntansi yang baik dan benar dapat memberikan pedoman kepada pihak manajemen untuk melaksanakan tugasnya dengan baik. Dengan adanya 
sistem informasi akuntansi yang memadai diharapkan dapat menjamin proses pemberian kredit, sehingga dapat mencegah risiko kerugian yang diakibatkan oleh macetnya pembayaran kredit atau mencegah pemberian kredit dengan cara yang tidak sehat. Risiko ini disebabkan oleh analisis kredit yang tidak sempurna, penilaian anggunan dan peninjauan anggunan yang kurang tepat, penyelesaian kredit bermasalah yang kurang efektif dan risiko-risiko lain yang timbul akibat pengendalian internal dalam pengendalian kredit tidak berjalan dengan benar. Pengendalian kredit pada Bank BTN belum berjalan secara maksimal yang berakibat pada penurunan tingkat kesehatan operasi bank, ketidaktelitian Bank BTN dalam menganalisi kredit baik pada prosedur persayaratan atau kebijaksaan yang diberikan akan mengakibatkan pengelolaan kredit yang kurang efektif yang menyebabkan meningkatnya kredit macet, hal ini menyebabkan perlu adanya pembetulan atau peninjauan kembali untuk meminimalisir risiko. BTN Tingkatkan Kontrol Internal demi Keamanan dan Kenyamanan Nasabah (ekbis.sindonews.com). Bank BTN harus menerapkan kontrol kredit yang memadai untuk meminimalkan peluang negatif yang mungkin timbul, seperti penipuan atau penipuan dalam proses pinjaman, baik akuntansi maupun administrasi, sehingga pinjaman yang dikeluarkan dapat benar dan dijamin. pembayaran pinjaman tepat waktu sesuai dengan kontrak, baik dasar dan bunga.

\section{Kajian Pustaka}

\section{Pengertian Sistem, Informasi dan Akuntansi}

Sistem merupakan kumpulan subsitem, bagian atau komponen yang berhungan antara satu dengan yang lainnya dan bekerja bersama secara harmonis dalam mencapai suatu tujuan tertentu melalui tiga tahapan input, proses dan output (Susanto, 2013:22).

\section{Informasi}

Informasi merupakan data yang telah disederhanakan dan diproses terkait dengan mereka yang menerima, untuk meningkatkan proses pengambilan keputusan. Seseorang dapat buat keputusan yang tepat kerana kuantitas dan kualitas informas (Romney, 2014:4).

\section{Akuntansi}

Akuntansi adalah identifikasi, pengumpulan dan penyimpanan data, yang meliputi proses pengembangan informasi, pengukuran, dan proses komunikasi. Akuntansi adalah sistem informasi yang mengumpulkan, mencatat, dan menyimpan data yang menghasilkan informasi untuk pengambilan keputusan. (Romney 2014:11).

\section{Sistem Informasi Akuntansi \\ Pengertian Sistem Informasi Akuntansi}

Sistem informasi akuntansi adalah sistem yang memproses data dan transaksi keuangan untuk memperoleh informasi yang berguna ketika merencanakan, mengendalikan, dan mengelola bisnis. (Krismiaji 2010:4). Sistem informasi akuntansi adalah seperangkat subsistem dalam bentuk fisik dan nonfisik, yang saling berhubungan satu sama lain untuk memproses data tentang transaksi yang berkaitan dengan masalah keuangan dalam informasi keuangan yang diperlukan untuk manajemen dalam proses pengambilan keputusan. (Susanto 2013:72).

\section{Pengendalian Internal}

\section{Pengertian Pengendalian Internal}

Pengendalian internal proses untuk mempengaruhi ataupun mengarahkan aktivitas kepada sebuah objek, organisasi atau sistem (Krismiaji 2010:215). Sedangkan menurut ahli lain pengendalian internal yaitu suata rencana organisasi dan metode bisnis yang digunakan untuk melindungi aset, memberikan informasi yang akurat dan dapat diandalkan, mempromosikan dan meningkatkan efisiensi, dan mendorong kepatuhan dengan kebijakan yang ditetapkan (Romney 2006:229).

\section{Komponen Pengendalian Internal}

Menurut Committee of Sponsoring Organizations (COSO) dalam Romney (2014:221) ada 5 komponen pengendalian internal yaitu:

1. Lingkungan Pengendalian

2. Penilaian Resiko

3. Aktivitas Pengendalian

4. Informasi dan Komunikasi

5. Pemantauan 


\section{Kredit}

\section{Pengertian Kredit}

Mulyadi (2008:113) menyatakan kredit merupakan pemberian kredit kepada pelanggan dalam bentuk pinjaman tunai atau non tunai. Menurut Undang-Undang Perbankan Dasar No. 10 tahun 1998, pinjaman adalah penyediaan uang atau wesel yang setara berdasarkan perjanjian pinjaman atau perjanjian antara bank dan pihak lain yang mengharuskan pihak yang memberikan pinjaman untuk melunasi hutang setelah jangka waktu tertentu.

\section{Fungsi Dan Tujuan Kredit}

Fungsi suatu fasilitas kredit memeliki fungsifungsi (Kasmir 2008:100) sebagai berikut:

1. Meningkatkan daya guna uang

2. Meningkatkan peredaran dan lalu lintas uang

3. Meningkatkan daya guna barang

4. Meningkatkan peredaran uang

5. Sebagai alat stabilitas ekonomi

6. Meningkatkan kegairahan berusaha

7. Meningkatkan pemerataan pendapatan.

\section{Penelitian Sebelumnya}

Faradila A. Salim telah melakukan penelitian terhadap penerapan sistem informasi akuntansi dalam mendukung pengendalian internal pemberian kredit pada PT Bank Bukopin Manado pada tahun 2015. Dari penelitan tersebut Faradila A. Salim mendapat hasil yaitu ketika memberikan pinjaman kepada PT Bank Bukopin Manado, klien harus mengisi formulir aplikasi pinjaman, setelah itu bank akan melakukan analisis dalam bentuk wawancara, pemeriksaan dan evaluasi sebelum membuat keputusan mengenai pinjaman tersebut. Nesti Angelica, Hendry Jaya dan Rizki Eka Putra (2016) melakukan penelitian terhadap Analisis Sistem Pengendalian Internal Pada Proses Pemberian Kredit Di PT Bank Rakyat Indonesia. Tbk Cabang Batam. Penelitian ini menggunakan alat analisis berupa analisis dokumentasi, observasi dan wawancara. Hasil dari penelitian tersebut adalah sistem pengendalian internal pada Bank BRI Batam sudah diterapkan secara efektif dengan telah diterapkannya pedoman dan standard sistem pengendalian internal baik menurut COSO (Commitee Of Sponsoring Organization of The Treadway Commission) maupun Bank Indonesia.

\section{Metode Penelitian \\ Lokasi Penelitian}

Dalam melakukan penelitian ini penulis medapatkan data dan informasi dari PT Bank Tabungan Negara (BTN) yang beralamat di jalan Sri Ratu Safiatuddin No. 19-23 Gampong Peunayong, Banda Aceh.

\section{Data Dan Teknik Pengumpulan Data}

Penelitian deskriptif kualitatif pada dasarnya data berupa kata-kata lisan atau tulisan tentang tingkah laku manusia yang dapat diamati (Taylor dan Bodgan, 1984). Menurut Patton (1990), data tersebut dapat dibagi menjadi tiga jenis, yaitu sebagai berikut:

1. Hasil pengamatan

2. Hasil pembicaraan

3. Bahan tertulis

Teknik pengumpulan data yang digunakan dalam penelitian ini adalah:

1. Wawancara

2. Dokumentasi

\section{Metode Analisa Data}

Metode analisa data pada penelitian ini adalah dengan melakukan metode deskriptif yaitu membandingkan teori-teori dan konsep-konsep yang ada dengan fakta di lapangan. Dari data yang telah terkumpul kemudian dianalisa dan diinterpretasikan untuk mengetahui kesesuaian dengan teori supaya dapat ditarik kesimpulan.

Ada tiga cara analisis data kualitatif, yaitu reduksi data, penyajian data dan penarikan kesimpulan (Miles dan Huberman, 1992). Reduksi data adalah proses memilih data dengan penekanan pada penyederhanaan, pengabstrakan, dan transformasi data kasar yang muncul dari catatan yang ditulis di lapangan. Metode reduksi data adalah berbukit yang sama: (1) pemilihan data yang ketat, (2) deskripsi pendek atau urain pendek, (3) klasifikasi menurut skema yang lebih luas.

\section{Pembahasan}

\section{Hasil Penelitian}

Sistem Informasi Akuntansi pada Prosedur Pemberian Kredit PT Bank Tabungan Negara

Sistem informasi akuntansi dibuat dan dijalankan oleh perusahaan untuk memberikan informasi kepada pihak manajemen perusahaan. Bank 
BTN telah melaksanakan sistem informasi akuntansi yang efektif untuk mempermudah manajemen perusahaan dalam mengambil keputusan pemberian kredit kepada nasabah atau pemohon kredit, Bank BTN melaksanakan beberapa prosedur sebagai berikut dalam pemberian kredit kepada pemohon kredit:

1) Prosedur permohonan kredit

Pemohon kredit harus memenuhi persyaratan dan ketentuan yang telah ditentukan oleh pihak Bank BTN agar permohonan kredit dapat segera diproses. Persyaratan dan ketentuan yang harus dipenuhi oleh pemohon kredit yaitu:

a) WNI berusia 21 tahun atau telah menikah

b) Usia pemohon tidak melebih 65 tahun pada saat kredit jatuh tempo.

c) Pemohon maupun pasangan (suami/istri) tidak memiliki rumah dan belum pernah mendapatkan subsidi pemerintah untuk kepemilikan rumah.

d) Gaji/penghasilan pokok tidak melebihi:

- Rp 4.000.000 (empat juta rupiah) untuk Rumah Sejahtera Tapak

- Rp 7.000.000 (tujuh juta rupiah) untuk Rumah Sejahtera Susun)

e) Memiliki e-KTP dan terdaftar di Dukcapil

f) Memiliki NPWP dan SPT Tahunan PPh orang pribadi sesuai dengan perundangundangan yang berlaku

g) Pengembang wajib terdaftar di Kementerian PUPR

h) Spesifikasi rumah sesuai dengan peraturan pemerintah

Adapun dokumen yang harus dilengkapi yaitu:

a) Formulir pengajuan kredit dilengkapi dengan pas photo terbaru pemohon dan pasangan

b) FC e-KTP/ Kartu Identittas

c) FC Kartu Keluarga

d) FC Surat Nikah/Cerai

e) Dokumen pengahasilan untuk pegawai:

- Slip gaji 3 bulan terakhir / Surat Keterangan Penghasilan

- FC SK Pengangkatan Pegawai Tetap/Surat Keterangan Kerja (apabila pemohon berkerja di instansi)

f) Dokumen penghasilan untuk wiraswasta:

- SIUP, TDP

- Laporan/ Catatan Keuangan 3 bulan terakhir g) Dokumen penghasilan untuk pekerja mandiri - FC Izin Praktek

h) Rekening Koran 3 bulan terakhir

i) FC NPWP/SPT PPh 21

j) Surat pernyataan penghasilan yang di tandatangani pemohon di atas materai dan diketahui oleh pimpinan instansi tempat bekerja atau kepala desa/lurah setempat untuk masyarakat berpenghasilan tetap

k) Surat pernyataan tidak memiliki rumah yang diketahui instansi tempat berkerja/lurah tempat KTP diterbitkan

1) Surat Keterangan Domisili dari kelurahan setempat apabila tidak bertempat tinggal sesuai KTP

Data yang diisi oleh pemohon kredit harus data yang benar dan akurat. Semua dokumen-dokumen harus dilengkapi sesuai dengan syarat dan ketentuan Bank BTN, dokumen tersebut merupakan monitoring yang wajib harus diisi oleh pihak Bank BTN ke dalam sistem, apabila dokumen tidak lengkap maka Bank BTN tidak dapat memproses pengajuan kredit pemohon. Dokumen-dokumen pemohon kredit KPR biasanya diantar langsung oleh pihak developer rumah.

2) Prosedur Penyidikan dan Analisa Kredit

Prosedur penyidikan dan analisa kredit dilakukan oleh petugas yang berbeda. Tugas penyelidik yaitu:

a) Melakukan survey terhadap kondisi usaha atau pekerjaan debitur di lokasi usaha atau tempat kerja debitur

b) Melakukan survey terhadap rumah untuk menilai anggunan berupa harga jual rumah, tipe bangunan dan luas tanah.

Tugas Analis Kredit yaitu:

a) Melakukan pengecekan terhadap dokumen pemohon

b) Melakukan pengecekan pada laporan BIChecking sesuai dengan sistem OJK (Otoritas Jasa Keuangan)

c) Melakukan pengecekan terhadap penghasilan apakah sesuai dengan anggunan

3) Prosedur Keputusan Pemberian Kredit

Ada beberapa tingkat pemutus kredit yaitu:

- MCLU Head (Mortgage Commercial Lending dab Unit Head) untuk batas kredit Rp 200.000.000 (dua ratus juta rupiah). 
- DMB Business (Deputi Branch Manager Business) untuk kredit diatas Rp 200.000.000 (dua ratus juta rupiah).

4) Prosedur Persetujuan Pemberian Kredit

Setelah pemutusan permohanan kredit, maka pihak bank mengeluarkan SP3K (Surat Penegasan Persetujuan Penyediaan Kredit) merupakan tanda disetujuinya permohonan kredit yang diajukan oleh pemohon. Pihak bank akan menghubungi pemohon kredit untuk membicarakan lebih lanjut mengenai syarat dan ketentuan yang tercantum dalam SP3K serta pemohon juga membuka buku rekening bank, setelah syarat dan ketentuan dipenuhi oleh pemohon kredit maka pihak bank dan pemohon kredit akan melakukan akad. Pemohon kredit akan menandatangani surat perjanjian kredit yang berisi tentang peraturaperaturan yang harus ditaati oleh pemohon kredit serta pemohon kredit juga akan menandatangani pengikat jaminan kredit.

5) Prosedur Pelunasan Kredit

Pemohon kredit setiap bulannya mendebit uang ke dalam buku rekeningnya sesuai dengan jumlah angsuran per bulan yang telah ditetapkan dalam SP3K. Pemohon kredit juga dapat mempercepat pelunasan kreditnya minimal setelah kredit pemohon berjalan selama 2 tahun dengan minimal pembayaran Rp.2.000.000,- (dua juta rupiah)

\section{Pembahasan}

\section{Pengendalian Internal Pemberian Kredit Pada PT Bank Tabungan Negara}

Pengendalian internal merupakan cara yang diterapkan dalam organisasi maupun perusahaan untuk melindungi aset, berikan informasi handal dan akurat. Pengendalian internal dirancang untuk memberikan kepastian yang berasalan terkait dengan pencapaian sasaran. Bank BTN dapat dikatakan sudah melengkapi ke lima komponen pokok suatu sistem pengendalian internal yang efektif.

1) Lingkungan Pengendalian Internal Lingkungan pengendalian adalah fondasi dari komponen lainnya. Inti dari suatu bisnis adalah orang-orang yang berada di dalam lingkungan bisnis tersebut. Bank BTN memiliki kebijakan dan prosedur pemberian kredit yang dilaksanakan oleh orang-orang yang kompeten. Adanya pemisahan tugas dalam pemberian kredit merupakan bukti komitmen manajemen kompetensi para pegawai atau karyawan Bank BTN, seperti adanya struktur organisasi, serta pembagian otoritas sesuai dengan bidangnya. Struktur organisasi Bank BTN sudah tersusun secara baik dengan adanya pemisahan fungsi sehingga dapat meminimalisir terjadinya kecurangan atau penyimpangan terkait dengan proses pemberian kredit.

2) Penilaian Resiko

Analisis pemberian kredit yang dilaksanakan oleh Bank BTN telah terlaksana dengan baik, sehingga analisis tersebut dapat memberikan keputusan apakah permohonan pemohon kredit dapat disetujui atau ditolak kreditnya. Bank BTN melakukan pengecekan pada laporan BIChecking sesuai dengan sistem OJK (Otoritas Jasa Keuangan), Bank BTN melihat apakah riwayat kredit pemohon bersih atau tidak, jika bersih maka permohonan kreditnya akan dilanjutkan, tetapi jika sudah pernah berada didalam daftar hitam di bank lain yang masih tersisa pinjamannya, maka dokumen pemohon akan dikembalikan ke developer. Bank BTN juga akan meninjau atau mempertimbangkan kembali apabila ada pemohon kredit yang pernah mengalami macet kredit di bank lain namun hanya selama 3 hari atau seminggu, namun hal ini bukan berarti Bank BTN akan menyetujui pemohon kredit tersebut.

3) Aktivitas Pengendalian

Aktivitas Pengendalian pada Bank BTN dapat dikatakan sudah terkendali dengan adanya pemisahan tugas dan tanggung jawab dalam pemberian kredit, yaitu:

- Petugas Entri (learing Service), bertugas untuk memproses berkas nasabah, melayani keluhan nasabah, memproses asuransi, dan melakukan Akad KPR dengan nasabah.

- Analis kredit

- Appraisal

- OTS Penghasilan/Usaha

- Pemutus Kredit

Bank BTN akan melakukan penagihan dan pembinaan kepada nasabah apabila ada nasabah yang belum melakukan pembayaran kredit sehari setelah masa jatuh tempo kredit. Bank BTN juga akan memberikan surat peringatan 
pertama apabila nasabah tidak melakukan pembayaran kredit setelah akhir bulan, jika surat peringatan pertama telah diberikan namun nasabah tidak juga melakukan pembayaran kredit setelah 15 hari, maka akan diberikan surat peringatan kedua hingga surat peringatan ketiga, namun setalah diberikan surat peringatan ketiga nasabah juga tidak merespon pihak bank maka Bank BTN akan melelang anggunan nasabah.

Bank BTN juga memberikan asuransi kepada nasabahnya untuk perlindungan nasabah berupa asuransi jiwa, serta perlindungan kebakaran jika terjadi kebakaran di rumah klien.

4) Informasi dan Komunikasi

Bank BTN melakukan pengarahan dan pembinaan terhadap developer perumahan mengenai alur kerjasama antara pihak Bank BTN dan developer rumah, syarat-syarat dan ketentuan apa saja yang perlu dilengkapi atau dipenuhi oleh pihak developer rumah seperti data legalitas anggunan dan permohonan pemohon kredit. Bank BTN juga menginformasikan kepada nasabah apabila setoran kredit nasabah telah diterima oleh Bank BTN, serta Bank BTN juga menginformasikan nasabahnya tanggal jatuh tempo kredit setiap bulannya dengan cara mengimail nasabah.

5) Pemantauan

Bank BTN menetapkan karyawan untuk memantau efektifitas pengendalian agar pemberian kredit sesuai dengan prosedurprosedur pemberian kredit. Pemantauan ini dilakukan oleh bagian internal control dan karyawan Bank BTN yang berasal dari kantor pusat.

\section{Peranan Sistem Informasi Akuntansi Pemberian Kredit dalam Mendukung Pengendalian Internal}

Sistem informasi akuntansi dan pengendalian internal dibutuhkan oleh berbagai pihak di perusahaan dalam pengambilan keputusan pemberian kredit kepada klien. Tujuan sistem informasi akuntansi yaitu informasi yang dihasilakan sistem dapat mempermudah manajemen dan para pemakainya saat pengambilan keputusan. Sistem informasi akuntansi yang baik dan tepat dapat berfungsi sebagai panduan untuk memandu pelaksanaan tugasnya dengan baik. Dengan adanya sistem informasi akutansi yang sesuai diharapkan untuk menjamin proses pemberian kredit, sehingga dapat mencegah resiko kerugian yang diakibatkan oleh macetnya pembayaran kredit atau menghambat pemberian kredit dengan cara yang tidak baik.

Sistem informasi akuntansi sangat berperan sebagai mendukung pengendalian internal di Bank BTN, hal ini dapat dilihat melalui beberapa cara-cara pemberian kredit, dengan adanya prosedur pemberian kredit bank dapat meminimalisir adanya pemohon kredit yang kurang bertanggung jawab yang dapat mengakibatkan terjadinya resiko kredit macet. Melalui penyidikan dan analisa kredit, pihak Bank BTN dapat mengetahui apakah dokumen yang diberikan oleh pemohon kredit yang benar dan akurat.

Sistem informasi akuntansi yang dijalankan oleh Bank BTN telah sesuai dengan komponen-komponen sistem informasi akuntansi menurut Romney (2014:11) yang terdiri dari:

1) Orang yang menggunakan sistem Adanya karyawan Bank BTN yang menggunakan sistem untuk mengentri data pemohon kredit

2) Prosedur dan Instruksi

Pemohon kredit harus melalui beberapa tahapan prosedur kredit untuk mendapatkan kredit yang diinginkan, serta karyawan Bank BTN juga harus mengikuti instruksi-instruksi dalam mengumpulkan, memproses dan menyimpan data permohonan pemohon kredit.

3) Data tentang organisasi dan aktivitas bisnis Bank BTN memiliki data organisasi yang lengkap dan aktivitas bisnis yang jelas

4) Software yang digunakan untuk memproses data Bank BTN memiliki software untuk menginput/mengentri data pemohon kredit

5) Infrastruktur teknologi Informasi

Infrastruktur yang digunakan Bank BTN adalah komputer, telepon kantor, kalkulator, wifi, printer, dan CCTV

6) Pengendalian internal

Bank BTN memiliki brankas dan filling cabinet untuk menyimpan dokumen-dokumen pemohon kredit atau nasabah, serta Bank BTN juga memiliki karyawan bagian internal control. 


\section{Kesimpulan Dan Saran \\ Kesimpulan}

1) Sistem informasi akuntansi pemberian kredit yang diterapkan oleh PT Bank Tabungan Negara (BTN) Banda Aceh telah memadai hal ini dikarenakan Bank BTN melaksanakan prosedurprosedur berikut ini dalam pemberian kredit kepada pemohon kredit:

a) Prosedur pemohonan kredit

b) Prosedur penyidikan dan analisa kredit

c) Prosedur keputusan pemberian kredit

d) Prosedur persetujuan pemberian kredit

e) Prosedur pelunasan kredit

2) Pengendalian internal di Bank BTN Banda Aceh telah efektif dikarenakan Bank BTN telah memenuhi ke lima komponen pokok suatu sistem pengendalian internal yang efektif.

3) Sistem informasi akuntansi pemberian kredit telah berperan dalam mendukung pengendalian internal, hal ini dapat dilihat melalui tahapan prosedur pemberian kredit, dengan adanya prosedur pemberian kredit bank dapat meminimalisir adanya pemohon kredit yang kurang bertanggung jawab yang dapat mengakibatkan terjadinya resiko kredit macet. Melalui penyidikan dan analisa kredit, pihak Bank BTN dapat mengetahui apakah dokumen yang diberikan oleh pemohon kredit yang benar dan akurat.

\subsection{Saran}

1) Berdasarkan hasil penelitian prosedur-prosedur kredit yang dilaksanakan oleh Bank BTN telah dilaksanakan dengan baik, namun ada baiknya apabila ada pemohon kredit yang pernah mengalami macet kredit di bank lain, pihak Bank BTN melakukan penyelidikan lebih rinci seperti melakukan wawancara dengan pemohon kredit, melakukan survey ditempat kerja pemohon kredit serta melakukan wawancara dengan pimpinan atau rekan kerja pemohon kredit bagaimana kebiasaan pemohon kredit, untuk mengurangi resiko kredit macet apabila permohonan pemohon kredit disetujui.

2) Bank BTN sebaiknya tidak hanyak memberikan surat peringatan saja kepada nasabah, tapi juga memberikan sanksi berupa denda apabila nasabah tidak menghiraukan surat peringatan yang kedua yang telah diberikan oleh pihak Bank BTN, sehingga nasabah Bank BTN lebih mempunyai kewajiban terhadap pembayaran kreditnya.

3) Penilitian selanjutnya diharapkan agar meneliti lebih dari satu objek agar dapat dijadikan penelitian kuantitatid dan peneliti selanjutnya juga menambah referensi teori yang digunakan lebih banyak.

\section{Daftar Pustaka}

Anasthasia, Dhelia Dayu., Darmawan, Nyoman Ari Surya and Werastuti, Desak Nyoman Sri. 2015. Analisis Sistem Pengendalian Intern dalam Pemberian Kredit Mikro Pada PT. Bank Rakyat Indonesia (Persero), Tbk Unit Banyuasri. eJournal S1 Ak Universitas Pendidikan Ganesha. https://ejournal.undiksha.ac.id/index.php/S1ak/a rticle/download/4808/365. (Diakses pada tanggal 20 Oktober 2018).

Angelica, Nesti., Hendry Jaya and Rizki Eka Putra. 2016. Analisis Sistem Pengendalian Internal Pada Proses Pemberian Kredit Di PT. Bank Rakyat Indonesia Tbk Cabang Batam. Measuremen.

https://www.journal.unrika.ac.id/index.php/me asurement/article/download/930/757. (Diakses pada tanggal 20 Oktober 2018).

Anggraeni, Elisabet Yunaeti. 2017. Pengantar Sistem Informasi. ANDI. Yogyakarta.

Bodnar, George H, and William S. Hopwood. 2006. Sistem Informasi Akuntansi, Buku I. Penerbit salemba empat, Jakarta.

Gunarso, Avianto. 2012. Analisis Sistem Informasi Akuntansi Dan Sistem Pengendalian Internal Perkreditan Pada PT. BTPN MUR (Mitra Usaha Rakyat) TBK Cabang Pamanukan. Jurnal Akuntansi Universitas Gunadarma.http://publication.gunadarma.ac.id/b itstream/123456789/5700/1/jurnal\%20skripsi\%2 0avi.pdf. (Diakses pada tanggal 20 Oktober 2018).

Jogiyanto, H.M. 2013. Analisis dan Desain Sistem Informasi : Pendekatan tertruktur teori dan praktik aplikasi bisnis.Andi Offset. Yogyakarta.

Jogiyanto, H.M. 2010. Teori Portofolio dan Analisis Investasi. Edisi Ketujuh. BPFE. Yogyakarta.

Kasmir. 2008. Bank dan Lembaga Keuangan Lainnya. Edisi Revisi 2008. PT. RAJAGRAFINDO PERSADA. Jakarta.

Krismiaji. 2010. Sistem Informasi Akuntansi. UPP AMP YKPN. Yogyakarta.

Mulyadi. 2001. Sistem Akuntansi Edisi Tiga. Salemba Empat. Jakarta. 
Mulyadi, 2002, Auditing, Edisi keenam, Cetakan pertama , Salemba Empat. Jakarta.

Mulyadi. 2008. Sistem Akuntansi. Edisi Ketiga. Salemba Empat. Jakarta.

Mulyadi. 2010. Sistem Akuntansi, Edisi ke-3, Cetakan ke-5. Penerbit Salemba Empat, Jakarta.

Mursyidi. 2010. Akuntansi Dasar. Ghalia Indonesia. Bogor.

Rama, Dasaratha and Frederick Jones. 2011. Sistem Informasi Akuntansi. Salemba Empat. Jakarta.

Romney, Marshal B and Paul John Steinbart. (2014). Sistem Informasi Akuntansi, Edisi ketigabelas, Diterjemahkan oleh : Kikin Sakinah, Nur Safira dan Novita Puspasari, Penerbit Salemba Empat, Jakarta.

Romney Marshall and Steinbart, 2012, Accounting Information System (12th Edition). Prentice Hall. London.

Romney Marshall and Steinbart, 2006, Accounting Information System (12th Edition). Prentice Hall. London.

Susanto. 2013. Sistem Informasi Akuntansi. Lingga Jaya. Bandung.

Salim, Faradila A. 2015. Analisis Penerapan Sistem Informasi Akuntansi dalam Mendukung Pengendalian Internal Pemberian Kredit Pada PT Bank Bukopin Manado. Jurnal EMBA. http://download.portalgaruda.org/article.php?arti $\mathrm{cle}=316088 \& \mathrm{val}=1025 \& \mathrm{titl}=$ ANALISIS $\% 20 \mathrm{P}$ ENERAPAN\%20SITEM\%20INFORMASI\%20 AKUNTANSI\%20DALAM\%20MENDUKUN G\%20PENGENDALIAN\%20INTERNAL $\% 20$ PEMBERIAN\%20KREDIT\%20PADA\% $20 \% 20$ PT.\%20BANK\%20BUKOPIN\%20MANADO. Diakses 20 Oktober 2018. Hal.1034-1043.

Taufiq, Rohmat. 2013. Sistem Informasi Manajemen, Konsep Dasar, Analisis dan Metode Pengembangan. Graha Ilmu. Yogyakarta.

Yakub. 2012. Pengantar Sistem Informasi. Edisi 1. Grahallmu. Yogyakarta.

https://www.bphn.go.id/data/documents/98uu010.pdf 